\title{
Effect of taurine supplementation on fat and energy absorption in cystic fibrosis
}

\author{
M De Curtis, F Santamaria, P Ercolini, L Vittoria, G De Ritis, V Garofalo, F Ciccimarra
}

\begin{abstract}
In 10 children with cystic fibrosis and persisting steatorrhoea, supplementation with taurine (30-40 $\mathrm{mg} / \mathrm{kg} / \mathrm{day}$ ) was given for two months as an adjunct to the usual pancreatic enzyme treatment. A three day fat and energy balance was performed in patients with cystic fibrosis, before and after the supplementation, and in seven healthy controls who did not receive taurine.

Faecal fat was measured by a gravimetric method and stool energy was determined using a bomb calorimeter. Patients with cystic fibrosis, before and after taurine, and healthy controls received the same fat and energy intake (calculated by a dietitian). In patients with cystic fibrosis taurine did not produce any improvement of steatorrhoea (mean (SD) faecal fat $8.7(3.3) v 11.2(7.0) \mathrm{g} /$ day, respectively before and after the supplementation), of faecal energy loss $(0.978(0.468) v 1.133$ $(0.539) \mathrm{MJ} /$ day), of faecal fat expressed as percent of fat intake $(13.4(5.6) v 15.1(9.8) \%)$, and of faecal energy expressed as percent of energy intake $(9.9 \quad(3.6) \quad v \quad 11.2 \quad(5 \cdot 7) \%)$ Healthy controls had significant lower fat (3.5 $(2.3) \mathrm{g} /$ day) and energy $0.576(0.355) \mathrm{MJ} /$ day faecal losses.

In conclusion, taurine failed to decrease significantly fat and energy losses. Our study does not support the use of taurine supplementation in the nutritional management of cystic fibrosis.
\end{abstract}

(Arch Dis Child 1992;67:1082-5)

The best known gastrointestinal complication of cystic fibrosis is pancreatic deficiency, which is present in $85 \%$ to $95 \%$ of patients. ${ }^{1}$ When untreated, pancreatic insufficiency may be responsible for a high degree of morbidity and may affect growth and nutrition. Adequate pancreatic enzyme replacement is required in order to correct nutrient malabsorption, but fat absorption often remains suboptimal despite the use of pancreatic extracts and of drugs which affect duodenal acidity.

As the predominance of glycine bile acid conjugates with almost complete disappearance of tauroconjugates could play a part in the fat malabsorption in cystic fibrosis, ${ }^{2}$ taurine supplementation has been proposed as an adjunct to standard treatment. Nevertheless, the results of published papers are conflicting. A significant improvement of fat absorption after taurine supplementation was demonstrated by two different groups, ${ }^{3-5}$ whereas the studies of Thompson et al concluded that taurine is not indicated in the nutritional management of cystic fibrosis. ${ }^{6} 7$ In addition to this, Fitzpatrick et al were unable to demonstrate a change in fat solubilisation in patients with cystic fibrosis with ileal resection after taurine supplementation. $^{8}$

To determine whether taurine could play a part in fat malabsorption in cystic fibrosis, we studied the effect of taurine on fat and energy malabsorption in a group of patients with cystic fibrosis with various degrees of intestinal malabsorption that were only in part corrected by pancreatic extracts.

\section{Patients and methods \\ PATIENTS}

Ten patients with cystic fibrosis, seven boys and three girls, with a mean age of $7 \cdot 7$ years (range 2-13 years) were admitted to the study. The inclusion criteria were the persisting clinical symptoms due to an inadequate correction of the pancreatic insufficiency despite the enzyme replacement (mainly, persisting steatorrhoea and failure to gain weight while on an unrestricted diet). The patients had a Shwachman clinical score ranging between 45 and 96 (mean 71) and a degree of respiratory involvement judged from mild to severe. No ileal resection had previously been performed. No patient had clinical and biochemical signs of liver and biliary tract diseases and no one had a weight: height ratio $<5$ th centile. Vitamin supplementation, aerosol treatment, and physiotherapy were unchanged during the study.

All patients were supplemented with an enteric coated enzyme preparation of pancreatin (Pancrease, Cilag). The number of capsules, ranging from a minimum of six to a maximum of 20 a day in the whole study group, remained the same during the study.

\section{DESIGN OF THE STUDY}

The experiment was performed on an ambulatory basis and the patients, who were well at the time of the study, remained clinically stable for the whole period of supplementation. Taurine (O-Due, Nativelle) was administered for two months twice daily at a dose of $30-40 \mathrm{mg} / \mathrm{kg} / \mathrm{day}$ as suggested by Darling et $a l .^{4}$

Before and two months after starting the supplementation a fat and energy balance study was performed in each patient. Weighed food intake was recorded for a period of six days by a daily diary and a dietitian controlled the records to check for errors. The weighed food intake was anaiysed using food composition data. ${ }^{9}$ 
Gross energy intakes were estimated by multiplying the intakes of fat $(39.3 \mathrm{~kJ} / \mathrm{g})$, protein (as nitrogen $\times 6.25 ; 23.6 \mathrm{~kJ} / \mathrm{g}$ ), and carbohydrate $(17.6 \mathrm{~kJ} / \mathrm{g})$ by their respective heat of combustion values. ${ }^{10}$ All stools, collected in the final three days of the record period, were kept in polyethylene bags and immediately frozen. Coal tablets were used as charcoal markers between the start and the end of the collection period.

All the patients were cooperative and no gross errors were found in the daily diary or the procedure for stool collection. During the collection periods the fat content of the diet was not different from the patients' usual diet (about $3 \mathrm{~g} / \mathrm{kg} /$ day).

A fat and energy balance study was also performed in seven healthy children, with a mean age of 10 years (range 6-12 years), who had no known gastrointestinal and metabolic diseases. They were studied as controls and did not receive taurine supplementation.

\section{ANALYSIS}

The pooled three day stools were weighed and dried in an oven at $99^{\circ} \mathrm{C}$ for 24 hours. The weight of the dried stool was recorded and expressed as a \% of wet stool.

Fat analyses were performed on the dried stool samples. A modification of the gravimetric method of Zuckerman et al was used. ${ }^{11}$ Four weighed samples of dried stools $(0.5-2 \mathrm{~g})$ were subjected to acid hydrolysis by boiling in $4 \mathrm{M}$ hydrochloric acid. The hydrolysate was filtered and the filter papers were washed with hot water until neutral $\mathrm{pH}$ was achieved. They were then dried and extracted with petroleum ether $\left(60-80^{\circ} \mathrm{C}\right)$ into preweighed aluminium cups. The extraction was performed in a Soxtec $\mathrm{Ht}$ 1043 extraction unit (Tecator). The cups containing the extracted fat were dried and weighed again, and the difference in cup weight was defined as the sample's fat content.

Energy was determined on dried stools using a ballistic bomb calorimeter (Gallenkamp) as reported elsewhere. ${ }^{12}$

Results are given as faecal fat (g/day), faecal energy (MJ/day), and \% of fat intake and \% of gross energy intake. All the values are expressed as mean (1SD).

The significance of the difference between two arithmetic means was evaluated with the paired and unpaired Student's $t$ test and differences between means were considered significant where $\mathrm{p}<0.05$.

\section{Results}

Taurine supplementation was well tolerated and no side effects were noted. All patients complied with the treatment, as written records of the daily consumption of taurine and of pancreatic extracts were reported by the parents.

In patients with cystic fibrosis daily fat intake was not different in the two periods of stool collection (before taurine, 70.5 (22.5) g/day; after taurine, $76 \cdot 3(21 \cdot 3) \mathrm{g} /$ day). In healthy controls, fat intake was $79 \cdot 4(27 \cdot 8) \mathrm{g} /$ day.

In patients with cystic fibrosis the weight of wet stools was not different before and after taurine supplementation (179 (116) v 168 (61) g/day). The dry weight expressed as a $\%$ of wet weight in both groups was $24 \cdot 1(4 \cdot 4) v 25 \cdot 8$ $(5 \cdot 6) \%$, respectively. In healthy controls the weight of wet stools was 141 (101) g/day and the dry weight $20.5(5 \cdot 1) \%$ of faecal wet weight.

Data about faecal fat losses in patients with cystic fibrosis show that taurine administration did not improve faecal fat loss (before taurine, $8.7(3.3) \mathrm{g} /$ day; after taurine, $11 \cdot 2(7 \cdot 0) \mathrm{g} /$ day; $p<0.006)$. Values of faecal fat loss in healthy controls were significantly lower than those found in patients with cystic fibrosis before taurine $(3.5(2.3)$ g/day $v 8.7(3.3)$ g/day; p $<0.001$; fig 1).

As shown in fig 2 , in patients with cystic

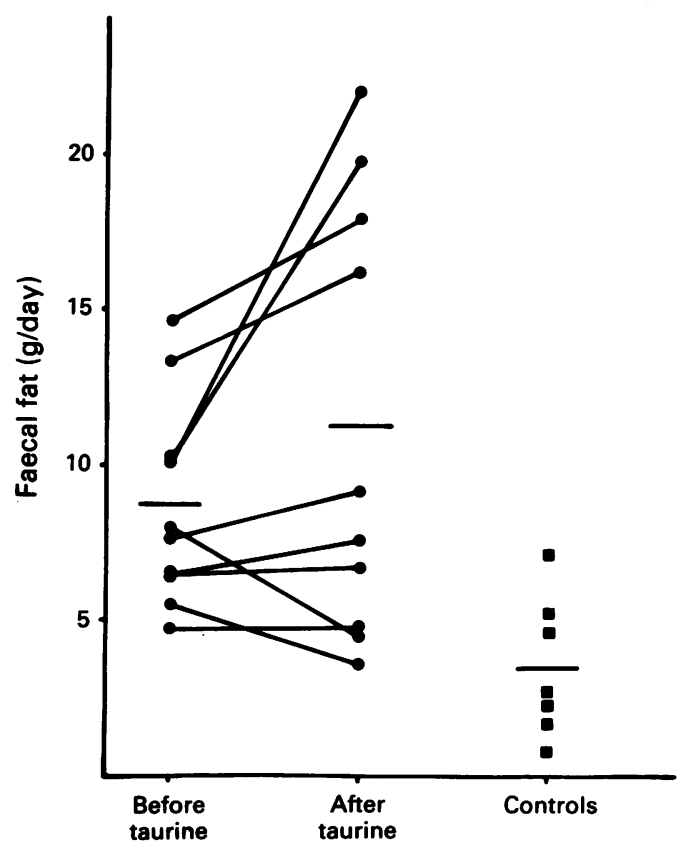

Figure I Daily stool fat expressed as g/day incystic fibrosis patients before and after taurine supplementation and in the control subjects. The bars represent the mean values.

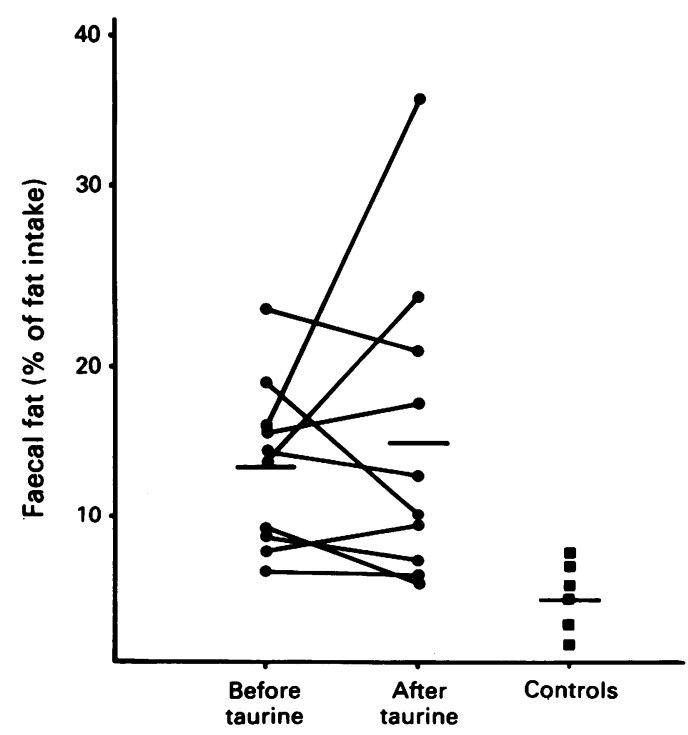

Figure 2 Daily stool fat expressed as \%of fat intake in cystic fibrosis patients before and after taurine supplementation and in the control subjects. The bars represent the meanvalues. 
fibrosis the faecal fat expressed as $\%$ of fat intake was $13 \cdot 4(5 \cdot 6) \%$ before taurine and $15 \cdot 1(9 \cdot 8) \%$ after taurine (the difference was not significant). In controls the faecal fat expressed as \% of fat intake was lower than in patients with cystic fibrosis $(4 \cdot 3(2 \cdot 2) \% ; p<0 \cdot 001)$.

Gross energy intake was $10 \cdot 111(2 \cdot 691) \mathrm{MJ} /$ day and $10.442(2.575) \mathrm{MJ} /$ day in patients with cystic fibrosis, respectively before and after taurine; in controls subjects it was 10.065 $(2 \cdot 215) \mathrm{MJ} /$ day.

In patients with cystic fibrosis, faecal energy loss was not different in the two periods (before taurine, $0.978(0.468) \mathrm{MJ} /$ day; after taurine,

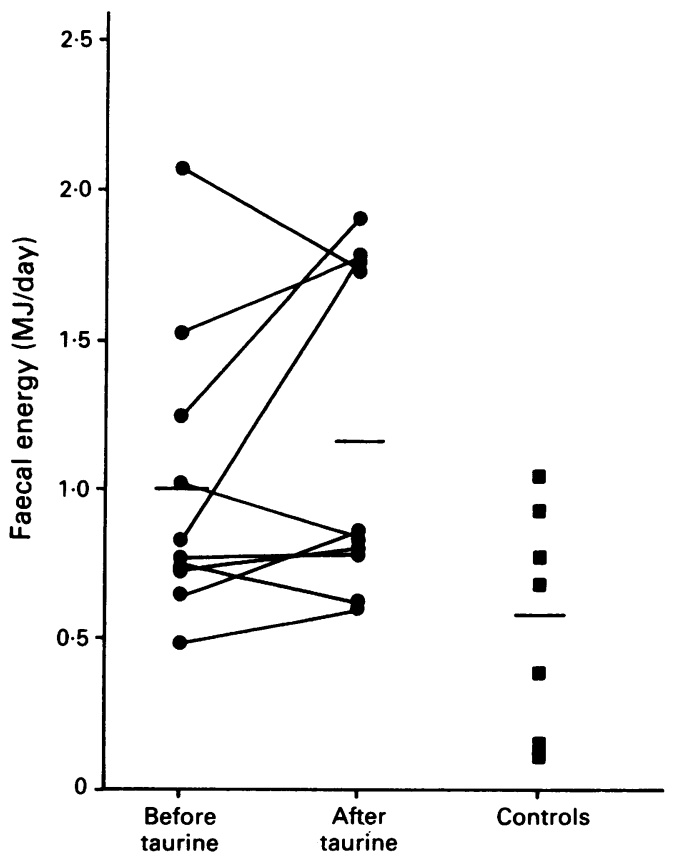

Figure 3 Dailystoolenergy losses expressed as MF/day in cystic fibrosis patients before and after taurine supplementation and in the control subjects. The bars represent the mean values.

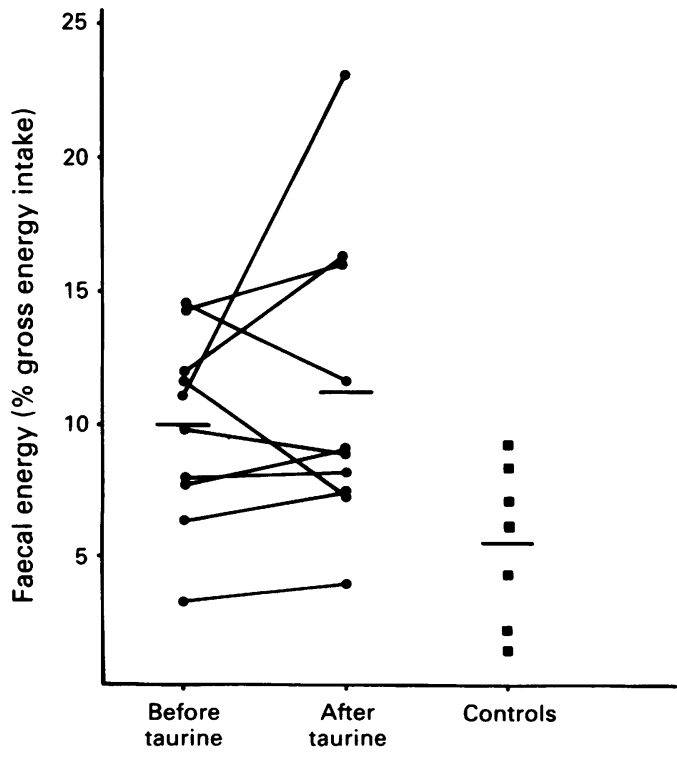

Figure 4 Dailystoolenergylosses expressed as a \% of the gross energy intake in cystic fibrosis patients before and after gross energy intake in cystic fibrosis patients before and after
taurine supplementation and in the control subjects. The bars represent the mean values.
$1 \cdot 133(0.539) \mathrm{MJ} /$ day $)$. Healthy controls had a mean faecal energy loss significantly lower than patients with cystic fibrosis $(0.576(0.355) \mathrm{MJ} /$ day $v 0.978(0.468) \mathrm{MJ} /$ day; $\mathrm{p}=0.037$; fig 3$)$.

As illustrated in fig 4 , in patients with cystic fibrosis faecal energy expressed as \% of gross energy intake did not change before and after taurine administration (respectively, 9.9 (3.6)\% $v 11 \cdot 2(5 \cdot 7) \%$; the difference was not significant). Healthy controls had a faecal energy expressed as $\%$ of gross energy intake significantly lower than patients with cystic fibrosis (5.5 (3.0); $p=0.009$ )

\section{Discussion}

To our knowledge this represents the first longitudinal study that measures both faecal lipid and energy losses in patients with cystic fibrosis before and after taurine supplementation. The main consequence of pancreatic insufficiency in cystic fibrosis is the failure to digest and absorb some components of the diet. Fat and nitrogen malabsorption are common in these patients and the faecal energy losses reflect the nutrients' malabsorption.

As enzyme replacement diminishes but does not normalise the amount of fat and nitrogen lost in stools, the use of other drugs that can improve fat malabsorption has been suggested in cystic fibrosis. ${ }^{13}$ Nevertheless, a definitive resolution of the symptoms due to steatorrhoea is rarely achieved. In this study we were unable to demonstrate that taurine leads to an improvement in the absorption of fat and energy in 10 children with cystic fibrosis who had persisting fat malabsorption despite appropriate enzyme treatment. These findings contrast with most of the reports about the use of taurine in cystic fibrosis, ${ }^{3-5}$ but are similar to the conclusions of other studies, which did not support the therapeutic use of taurine in the nutritional management of cystic fibrosis. ${ }^{6} 7$

The disagreement in the results of the studies on taurine supplementation in cystic fibrosis could be related to differences in the characteristics of the study population. People who suggest the use of taurine in cystic fibrosis recommend it particularly in patients with a significant degree of steatorrhoea, but our results, like those by Thompson et al,,$^{67}$ do not reveal any improvement in fat and energy absorption, even in cases with a low baseline high fat and energy losses.

The dose of taurine and the length of the supplementation cannot represent a bias: in our study taurine was given at the same dose and for the same period as in another study that concluded that taurine was effective in cystic fibrosis. ${ }^{5}$ However, Thompson et al showed that the glycine:taurine conjugates ratio is remarkably sensitive to even relatively small doses of taurine. ${ }^{7}$

Recently, another group has published data regarding the energy and fat content of stools in patients with cystic fibrosis. ${ }^{14}$ Similar values of both faecal fat and faecal energy have been found in our patients.

In healthy patients we found a slightly higher fat and energy faecal excretion than those 
reported by Murphy et al (respectively $3.5 v 2 \cdot 2$ g/day and $0.577 v 0.339 \mathrm{MJ} /$ day). ${ }^{14}$ Our values are similar to those seen in adults. ${ }^{15}$

Faecal energy does not represent only malabsorbed energy: in addition to maldigested and unabsorbed dietary residues, faecal energy losses can be due in part to colonic bacteria and to products from cellular lysis, which represents up to $30 \%$ of the faecal energy. ${ }^{14}$

In our study, fat absorption was estimated in terms of steatorrhoea and of the percentage of dietary fat intake, which had been strictly checked by a dietitian. In the previous studies no detailed data about the dietary intake of fats are given: the variation of fat intake itself may account for changes in faecal fat loss unrelated to fat absorption. Furthermore, in one of these studies the authors give results in terms of 'steatorrhoea', that is quite different from the percent of fat intake.

In cystic fibrosis some evidence exists for impairment of fat absorption, which is distinct from the maldigestion of fat consequent on absence of pancreatic lipase. Some steatorrhoea may persist with enteric coated enzyme preparations, even when optimal intraluminal $\mathrm{pH}$ for exogenous lipase is achieved by the use of cimetidine and sodium bicarbonate. ${ }^{13} \mathrm{~A}$ reduction in the bile acids pool resulting from decreased ileal reabsorption may be a partial explanation. $^{2}$

The efficacy of taurine in cystic fibrosis is based on the assumption that this amino acid provides the necessary substrate for the synthesis of taurine-conjugated bile acids, which in turn, could improve the micellar solubilisation of lypolitic products. ${ }^{16}$ Our patients had no liver and biliary tract disease. Nevertheless, as ileal mucosal bile acids malabsorption has been postulated in cystic fibrosis, ${ }^{17}$ we cannot definitely state that our patients did not benefit from taurine supplementation because taurineconjugated bile acids are less efficiently absorbed across the ileum.

In our study a variability in the response to supplementation appears in some individual patients. An explanation for this and for the considerable variability of the response to taurine supplementation among the various groups ${ }^{3-7}$ is the great heterogeneity of fat malabsorption in cystic fibrosis, which can be due both to lipase deficiency and to decreased solubility of bile acids micelles in the unstirred water layer. In this view the hypothesis of the association between taurine deficiency and biliary abnormalities in some patients with cystic fibrosis appears interesting. This finding supports the conclusion that taurine could be helpful only in selected patients, particularly if fat malabsorption is more related to the bile acid component than to the exocrine pancreatic insufficiency itself.

Taurine supplementation is also a controver- sial issue in low birthweight infants, who usually present with a low fat absorption. ${ }^{18}$ The reasons for fat malabsorption in these babies are various and not fully defined: pancreatic lipase may be reduced, bile acid pool sizes, rate of synthesis and intraluminal concentrations are low, and absorption of bile salts may be impaired. No agreement has been reached about the effectiveness of supplementation of formulas with taurine on fat absorption in low birthweight infants. ${ }^{18-20}$

In conclusion, pending further studies on taurine administration in cystic fibrosis, we do not recommend an indiscriminate supplementation with taurine in every patient with cystic fibrosis suffering from persisting steatorrhoea. More work is still necessary to confirm the exact role of taurine in cystic fibrosis.

1 Boat TF, Welsh MJ, Beaudet AL. Cystic fibrosis. In: Scriver $\mathrm{CR}$, Beaudet AL, Sly WL, Valle D, eds. The metabolic basis of inherited disease. New York: McGraw-Hill, 1989: 2649-76.

2 Weber AM, Roy CC, Morin CL, et al. Malabsorption of bile acids in children with cystic fibrosis. $N$ Engl $\mathcal{f}$ Med 1973; 289:1001-5.

3 Belli DC, Levy E, Darling P, et al. Taurine improves the absorption of a fat meal in patients with cystic fibrosis. Pediatrics 1987;80:517-23.

4 Darling PB, Lepage G, Leroy C, Masson P, Roy CC. Effect of taurine supplements on fat absorption in cystic fibrosis. of taurine supplements on $\mathrm{f}$
Pediatr Res 1985;19:578-82.

5 Colombo C, Arlati S, Curcio L, et al. Effect of taurine supplementation on fat and bile acid absorption in patients with cystic fibrosis. Scand $\mathcal{f}$ Gastroenterol 1988;23 (suppl with cystic $151-6$

6 Thompson GN, Trevor AR, Davidson GP. Taurine supplementation, fat absorption and growth in cystic fibrosis. P Pediatr 1987;111:501-6.

7 Thompson GN. Failure of taurine to improve fat absorption in cystic fibrosis. F Inherited Metab Dis 1988;11 suppl 2: $158-60$

8 Fitzpatrick WJF, Zentler-Munro PL, Northfield TC. Ileal resection: effect of cimetidine and taurine on intrajejuna bile acid precipitation and lipid solubilisation. Gut 1986;27: 66-72.

9 Fidanza F, Liguori G. Nutrizione umana.Napoli: Idelson, 1981.

10 Merrill AL, Watt BK. Energy values of foods, basis and derivation. Washington: United States Department of Agriculture Handbook, 1955:74.

11 Zuckerman JL, Zymaris MC, Natelson S. Simple method for the determination of fecal fat and fatty acids. 7 Lab Clin Med 1949;34:282-6.

12 De Curtis M, Senterre J, Rigo J. Estimated and measured energy content of infant formulas. $\mathcal{J}$ Pediatr Gastroentero Nutr 1986;5:746-9.

13 Durie $P$, Bell $L$, Linton $W$, et al. Effect of cimetidine and sodium bicarbonate on pancreatic replacement therapy in cystic fibrosis. Gut 1980;21:778-86.

14 Murphy SL, Wootton SA, Bond SA, Jackson AA. Energy content of stools in normal healthy controls and patients with cystic fibrosis. Arch Dis Child 1991;66:495-500.

15 Wollaeger EE, Comfort MW, Osterberg AE. Total solids, fat and nitrogen in the feces III. A study of normal persons. Gastroenterology 1947;9:272-83.

16 Zentler-Murno PL, Fitzpatrick WJF, Batten SC, Northfield TC. Effect of intrajejunal acidity on acqueous phase bile acids and lipid concentration in pancreatic steatorrhea due acids and lipid concentration in pancric

17 Fondacaro JD, Heubi JE, Rello GFN. Intestinal bile acid malabsorption in cystic fibrosis: a primary mucosal cell malabsorption in cystic fibrosis:

18 Järvenpaa A-L. Feeding the low-birth-weight infant. IV Fat absorption as a function of diet and duodenal bile acids. Pediatrics 1983;72:684-9.

19 Okamoto E, Rassin DK, Zucker CL, Salen GS, Heird WC. Role of taurine in feeding the low-birth-weight infant f Pediatr 1984;104:936-40.

20 Galeano NF, Darling P, Lepace G, et al. Taurine supplementation of a premature formula improves fat absorption in preterm infants. Pediatr Res 1987;22:67-71. 